\title{
Wnt-3a regulates somite and tailbud formation in the mouse embryo
}

\author{
Shinji Takada, ${ }^{1}$ Kevin L. Stark, ${ }^{2}$ Martin J. Shea, ${ }^{3}$ Galya Vassileva, Jill A. McMahon, ${ }^{1}$ \\ and Andrew P. McMahon ${ }^{1}$ \\ Roche Institute of Molecular Biology, Roche Research Center, Nutley, New Jersey 07110 USA
}

\begin{abstract}
Amphibian studies have implicated Wnt signaling in the regulation of mesoderm formation, although direct evidence is lacking. We have characterized the expression of 12 mammalian Wnt-genes, identifying three that are expressed during gastrulation. Only one of these, $W n t-3 a$, is expressed extensively in cells fated to give rise to embryonic mesoderm, at egg cylinder stages. A likely null allele of Wnt-3a was generated by gene targeting. All Wnt-3a- $\mathrm{W}^{-}$nt-3a $\mathrm{a}^{-}$embryos lack caudal somites, have a disrupted notochord, and fail to form a tailbud. Thus, Wnt-3a may regulate dorsal (somitic) mesoderm fate and is required, by late primitive steak stages, for generation of all new embryonic mesoderm. Wnt-3a is also expressed in the dorsal CNS. Mutant embryos show CNS dysmorphology and ectopic expression of a dorsal CNS marker. We suggest that dysmorphology is secondary to the mesodermal and axial defects and that dorsal patterning of the CNS may be regulated by inductive signals arising from surface ectoderm.
\end{abstract}

[Key Words: Wnt; gastrulation; mesoderm formation; somite; tailbud; gene targeting]

Received November 9, 1993; revised version accepted December 8, 1993.

Cell-cell interaction plays an important role in the development of all organisms. In the vertebrate, considerable progress has been made in recent years in identifying peptide growth factors, which may mediate the early inductive interactions that result in patterning of the embryo (for review, see Jessell and Melton 1992; Slack and Tannahill 1992; McMahon 1993). Most of these studies have focused on the amphibian embryo, where the ease of experimental manipulation has led to important advances in our understanding of early inductive interactions, particularly those governing the generation of mesodermal components at gastrulation (for review, see Slack and Tannahill 1992; Sive 1993).

Mesoderm is formed as an annulus around the equator of the amphibian embryo in response to vegetal-derived, maternally encoded signals. Members of two growth factor families, fibroblast growth factor (FGF) and transforming growth factor- $\beta$ (TGF- $\beta$ ), are capable of inducing mesoderm formation in isolated explants of blastula animal caps, cells that do not normally generate mesoderm in the embryo. Thus, these factors are implicated in normal mesoderm induction in vivo. This conclusion is strengthened by the observed inhibition of mesoderm formation in embryos expressing dominant-negative forms of FGF (Amaya et al. 1991) and activin (a member of the TGF- $\beta$ superfamily; Hemmati-Brivanlou and Mel-

Present addresses: ${ }^{1}$ Department of Cellular and Developmental Biology, The Biological Laboratories, Harvard University, Cambridge, Massachusetts 02138 USA; ${ }^{2}$ Amgen, Inc., Thousand Oaks, California 91320 USA; ${ }^{3}$ Institute for Molecular Genetics, Baylor College of Medicine, Houston, Texas 77030 USA. ton 1992) receptors. Interestingly, mesoderm induction by FGFs and TGF- $\beta$-related factors is qualitatively different. FGF induces mostly ventral cell types, such as mesothelium and blood cells (Slack et al. 1987; Kimelman et al. 1988), whereas activin and $V g-1$ induce dorsal mesoderm of the notochord (Smith 1987; Smith et al. 1990; Sokol et al. 1990; Thompson and Melton 1993). All factors will induce somitic mesoderm.

Finally, inductive signals released during gastrulation by cells of the dorsal lip of the blastopore, the so-called Organizer region, are required to generate the full complement of dorsal mesodermal cell types. Thus, induction and patterning of the embryonic mesoderm probably result from the combined action of multiple signals, some of which appear to be localized in the cleaving and gastrulating embryo.

A third family of putative signaling molecules, the Wnt family, has also been implicated in embryonic mesoderm induction. Wnt genes are widely dispersed in invertebrate and vertebrate organisms. There are at least 15 vertebrate members; all encode likely secreted proteins, many of which are expressed during early vertebrate development (for review, see McMahon 1992; Nusse and Varmus 1992). Injection of RNAs encoding Wnt-1 or Wnt-8 into one- or two-cell amphibian eggs results in axis duplication or rescue of the entire axis in UV-irradiated, axial-deficient embryos (McMahon and Moon 1989; Smith and Harland 1991; Sokol et al. 1991). Both of these members are capable of inducing a new Organizer region or of acting as an Organizer-derived, dorsalizing signal, which either directly induces dorsal 
Regulation of gastrulation by Wnt-3a

mesoderm (Sokol et al. 1991) or, more likely, acts to modify the response of receiving cells to other peptide growth factors (Christian et al. 1992). However, although Wnt-1 and Wnt-8 are implicated in patterning of dorsal mesoderm, expression of these signals is inconsistent with this view.

Wnt-1 expression is restricted to the later arising central nervous system (CNS), where it regulates midbrain development (McMahon and Bradley 1990; Thomas and Capecchi 1990; Thomas et al. 1991; McMahon et al. 1992). In contrast, Wnt-8 is expressed during gastrulation but exclusively in ventral regions (Christian et al. 1991; Smith and Harland 1991). Moreover, recent experiments ectopically expressing Wnt-8, during gastrulation, suggest that its real function may actually lie in restricting induction of dorsal mesoderm (Christian and Moon 1993). There are several explanations to these apparently conflicting data. For example, ectopically expressed Wnt-1 and Wnt-8 may mimic the action of an endogenous Wnt ligand by interacting with the ligand's receptor. This would suggest that some, as yet unidentified, Wnt member does regulate dorsal mesoderm formation. Alternatively, Wnt-1 and Wnt-8 may trigger a receptormediated pathway that is not normally stimulated at these early embryonic stages. If such a receptor couples intracellularly to the bona fide dorsal mesoderm-inducing signaling pathway, this may potentially explain the observed results. As Wnt receptors have not been identified, this issue cannot be directly resolved. However, a better understanding of the spatial and temporal expression of Wnt signals that may regulate gastrulation is likely to be informative.

In the mouse, gastrulation is initiated at 6.5 days postcoitum (dpc) by the delamination of epiblast cells into the primitive streak at the posterior limit of the embryo (for review, see Beddington 1983). By mid-somite stages (9.25 to $9.5 \mathrm{dpc}$ in the mouse), the primitive streak is replaced by the tailbud, which consists of an aggregate of mesodermal precursors at the caudal extremity of the embryo. New mesoderm continues to arise from the tailbud for several days (Schoenwolf 1977). Thus, the generation and patterning of mesodermal cell types along the embryonic axis occurs over a relatively long period of time.

To determine whether Wnt signals participate in gastrulation in the mouse, we examined the expression of 12 members of the Wnt gene family. Three members, Wnt-3a, Wnt-5a, and Wnt-5b, are expressed in discrete spatial domains in the primitive streak, and expression persists into the tailbud. Expression of Wnt-5a and Wnt$5 b$ is largely restricted to extraembryonic mesoderm precursors from early to late egg cylinder stages. In contrast, Wnt-3a is also expressed in cells that generate the somites and lateral mesoderm, suggesting that Wnt-3a signaling may normally regulate the formation of these mesodermal cell types. To address the function of Wnt$3 a$, we generated a likely null allele by gene targeting. Analysis of Wnt-3a homozygous mutant embryos indicates that Wnt-3a plays a key role in the regulation of mammalian gastrulation.

\section{Results}

Wnt gene expression during mouse gastrulation

To analyze the expression of Wnt genes during mouse gastrulation, we performed in situ hybridization with probes specific to Wnt-3, Wnt-3a, Wnt-4, Wnt-5a, Wnt5b, Wnt-6, Wnt-7a, Wnt-7b, Wnt-10, and Wnt-11. Wnt-1 and Wnt-2 expression was analyzed in earlier studies (Wilkinson et al. 1987a; McMahon and McMahon 1989). Only Wnt-3a, Wnt-5a, and Wnt-5b are expressed in the primitive streak and tailbud (data not shown). To obtain a comprehensive understanding of the temporal and spatial pattern of these three members, we performed serial section in situ hybridization to egg cylinder-stage embryos and whole-mount in situ hybridization to late streak and early tailbud, somite-stage embryos. At the egg cylinder stage, Wnt expression patterns were mapped relative to expression of the Brachyury $(T)$ gene, one of the first genes to be activated at the onset of gastrulation (Herrmann 1991). Brachyury is implicated in mesodermal specification, possibly as a direct response to mesoderm-inducing factors (Cunliffe and Smith 1992), and is essential for development of the notochord and caudal axis (for review, see Herrmann 1992). Thus, Brachyury expression, which first occurs in both epiblast and mesoderm within the streak and then later in the head process, notochord, node, and tailbud, is an excellent temporal and spatial marker of gastrulation and, more specifically, of the formation of dorsal midline structures (Wilkinson et al. 1990; Herrmann 1991).

At early primitive streak stages in the mouse, when the $T$ gene is first expressed $(6.5 \mathrm{dpc}), W n t-5 a$ and $W n t-$ $5 b$ transcripts are detected-Wnt-5a, only in mesodermal cells, and Wnt-5b, in epiblast and mesoderm within the streak (Fig. 1). It is not clear whether cells, at this or any later stage, coexpress Wnt-5a and Wnt-5b as the in situ technique does not allow single-cell resolution. By $7.0 \mathrm{dpc}$, the primitive streak has elongated distally, and expression of the $T$ gene occupies the proximodistal extent of the streak but is restricted medially within the streak to epiblast and mesoderm cells (Fig. 1). Wnt-5a and $W n t-5 b$ remain posteriorly restricted. In transverse section, Wnt- $5 b$ expression is restricted to medial epiblast and mesoderm within the streak, whereas Wnt-5a expression is absent in epiblast and extends more laterally in the mesoderm with a broader distribution than $T$ gene expression (Fig. 1). Parasagittal sections at $7.0 \mathrm{dpc}$ only detect laterally distributed Wnt-5a expression (Fig. 1).

By the extended-streak stages $(7.5 \mathrm{dpc})$, the third Wnt member, Wnt-3a, is widely expressed within the streak. Hybridization is patchy, suggesting that not all cells express Wnt-3a, but expression extends along much of the length of the streak, its distal limit lying just anterior to the node (Fig. 1). Brachyury expression resembles that of Wnt $-3 a$ in the streak but extends anteriorly into the node and midline mesoderm of the head process (Fig. 1). Expression of Wnt-5a and Wnt-5b remains posteriorly localized up to $7.75 \mathrm{dpc}$, extending into newly formed extraembryonic mesoderm of the allantois (Fig. 1). In sum- 


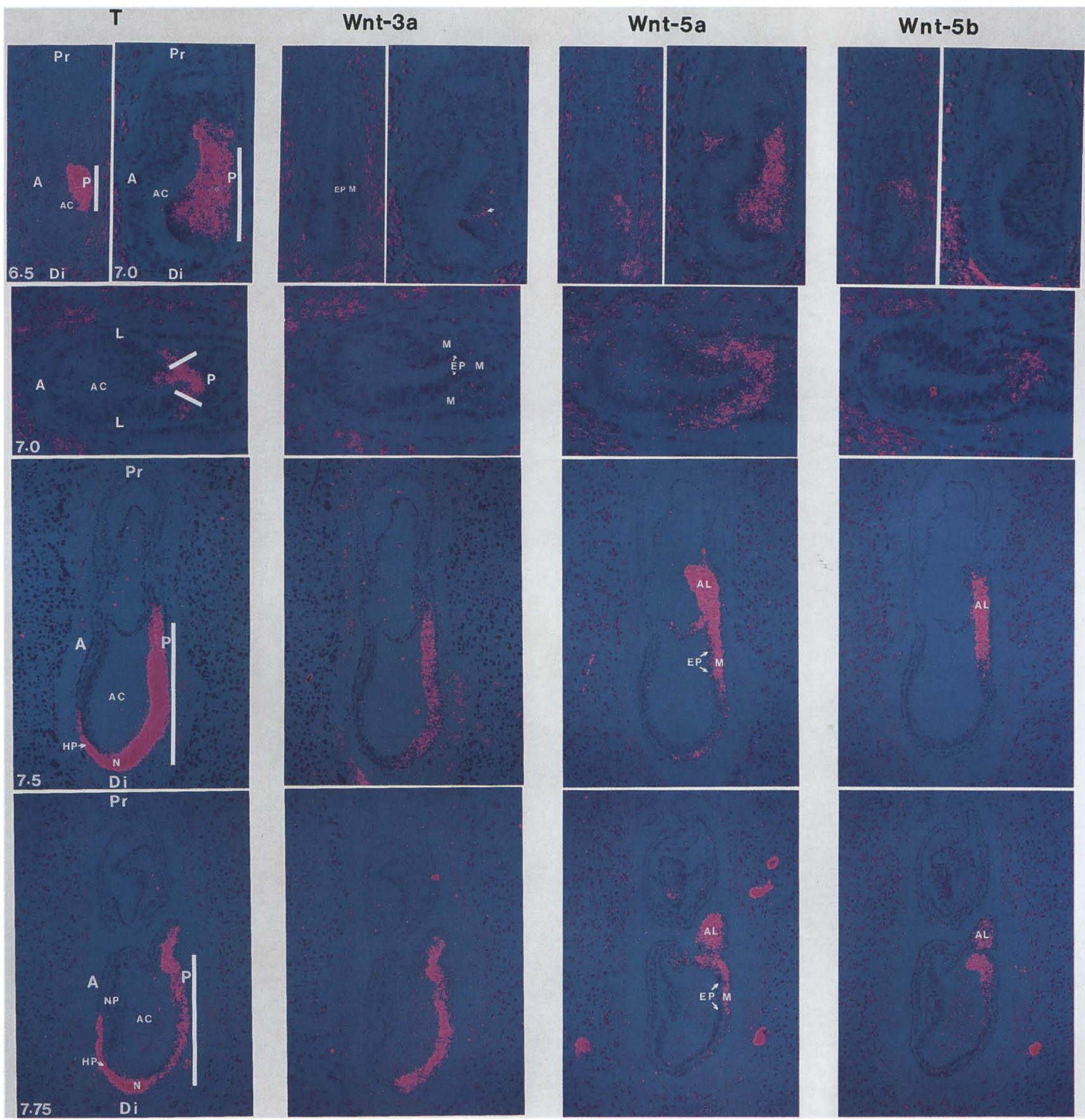

Figure 1. Expression of Brachyury (T gene), Wnt-3a, Wnt-5a, and Wnt-5b at egg cylinder stages of mouse gastrulation. Adjacent sagittal $(6.5,7.5$, and $7.75 \mathrm{dpc})$, parasagittal $(7.0 \mathrm{dpc})$, and transverse $(7.0 \mathrm{dpc})$ sections through the primitive streak region were hybridized with RNA probes specific to each gene. The approximate limits of the primitive streak are marked by the solid lines. The orientation of egg cylinder sections are as follows: (A) anterior; (Di) distal; (L) lateral; $(\mathrm{P})$ posterior; $(\mathrm{Pr})$ proximal. For a detailed description, see text. (AC) Amniotic cavity; (AL) allantois; (EP) epiblast; (HP) head process; (M) mesoderm; (N) node; (NP) neural plate. Initiation of Wnt-3a expression at $7.0 \mathrm{dpc}$ is indicated by the arrow. The apparent signal within the decidual tissue at several stages is not due to silver grains but is an artifact of tissue birefringence.

mary, expression of Wnt-5a and Wnt-5b from early to late egg cylinder stages is localized to posterior regions of the streak that cell fate studies indicate form extraembryonic mesoderm (see Discussion). In contrast, Wnt-3a expression extends more anteriorly, suggesting that
Wnt-3a may regulate the formation of embryonic mesoderm that is fated to arise from the anterior primitive streak (see Discussion).

Expression of all three Wnt genes continues in the late streak and tailbud of somite-stage embryos (Fig. 2). At 

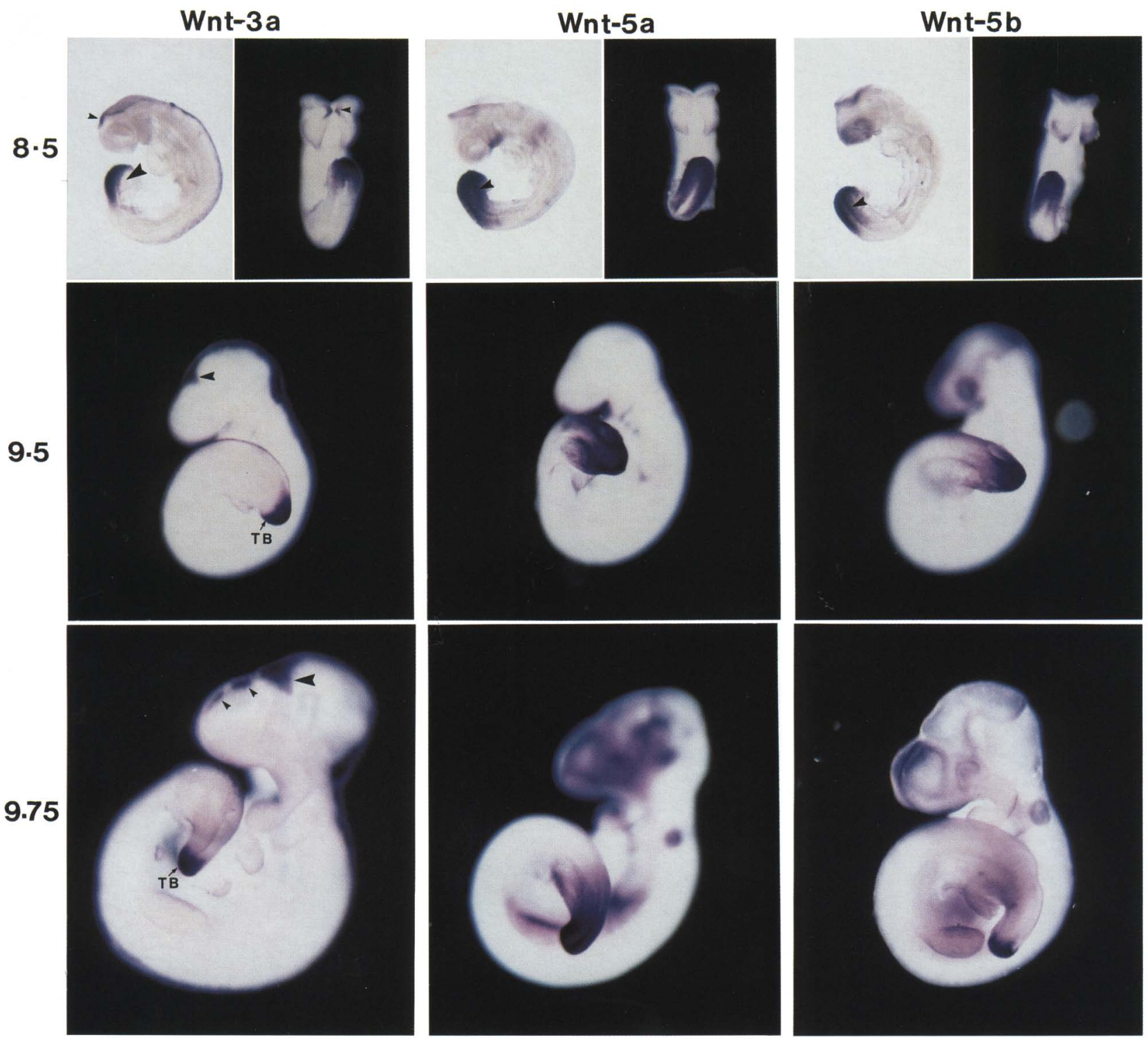

Figure 2. Expression of Wnt-3a, Wnt-5a, and Wnt-5b at somite stages. Whole-mount in situ hybridization with digoxygenin-labeled RNA probes specific to each gene. At $8.5 \mathrm{dpc}(10-11$ somites), all three Wnt genes are expressed dorsally in the primitive streak region, however, Wnt-3a, unlike Wnt-5a and Wnt-5b, is not expressed ventrally (large arrowhead). Wnt-3a expression is initiated in the dorsal diencephalon (small arrowhead). At $9.5 \mathrm{dpc}$ (22-26 somites) and 9.75 dpc (32-35 somites), Wnt-3a and Wnt-5b are localized exclusively to the tailbud (TB) region, whereas Wnt-5a expression extends more anteriorly in dorsal and ventral cells. At these stages, Wnt-3a expression extends ventrolaterally in a specific domain of the diencephalon (large arrowhead) and continues caudally along the entire neuraxis and rostrally into the dorsal telencephalon (small arrowhead).

early somite stages, Wnt-3a is expressed dorsally and caudally within the primitive streak, whereas Wnt-5a and $W n t-5 b$ expression extends rostral and ventral. As the primitive streak is lost and the tailbud forms, Wnt$3 a$ - and Wnt-5b-expressing cells are localized to the caudal-most tip of the tailbud, whereas Wnt-5a is expressed in a broader region. Thus, as the embryo undergoes a transition from primitive streak to tailbud, expression of Wnt-3a, Wnt-5a, and Wnt-5b is maintained in the region that continues to generate new mesoderm. In addition,
Wnt-3a is also expressed in the developing CNS / see be low).

\section{Targeting the Wnt-3a gene}

Of the three mouse Wnt genes, only Wnt-3a shows a clear association with the formation of embryonic mesoderm at egg cylinder stages. To address the function of Wnt-3a, we generated a likely null allele by gene targeting in mouse embryo stem (ES) cells. Figure 3A indicates 
Takada et al.

A Expected Restriction Fragments (kb.)
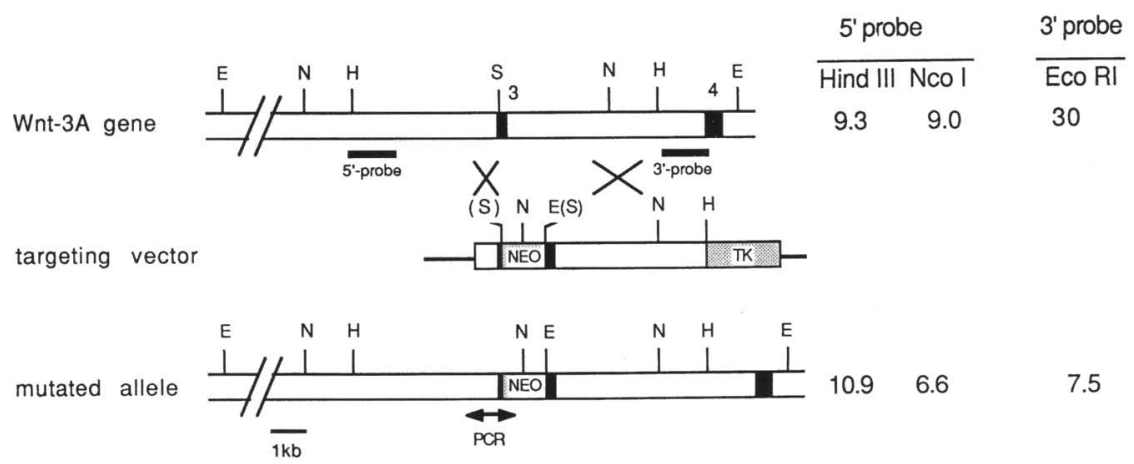

Figure 3. Gene targeting at the Wnt-3a locus. $(A)$ Schematic representation of the expected gene replacement at the Wnt-3a locus. The predicted size of diagnostic restriction fragments from the wild-type and targeted Wnt-3a alleles with $5^{\prime}$ and $3^{\prime}$ specific genomic probes are indicated, as well as the region used to initially identify homologous recombinant clones by PCR. $(B)$ Southern blot analysis of the targeted $8 \mathrm{~A}$ and 17A J7 ES cell lines. Both 5' and 3' probes detect restriction fragments indicative of the predicted gene replacement event at the Wnt-3a locus. (C) Southern blot analysis of the genotype of 9.5-dpc embryos from heterozygous intercrosses between Wnt-3a- $1+$ mice. Embryos were scored for normal $(\mathrm{N})$ or mutant $(\mathrm{M})$ phenotypes. The mutant phenotype, loss of somites and axial truncation, was only ob-

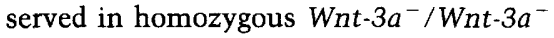
embryos.
B
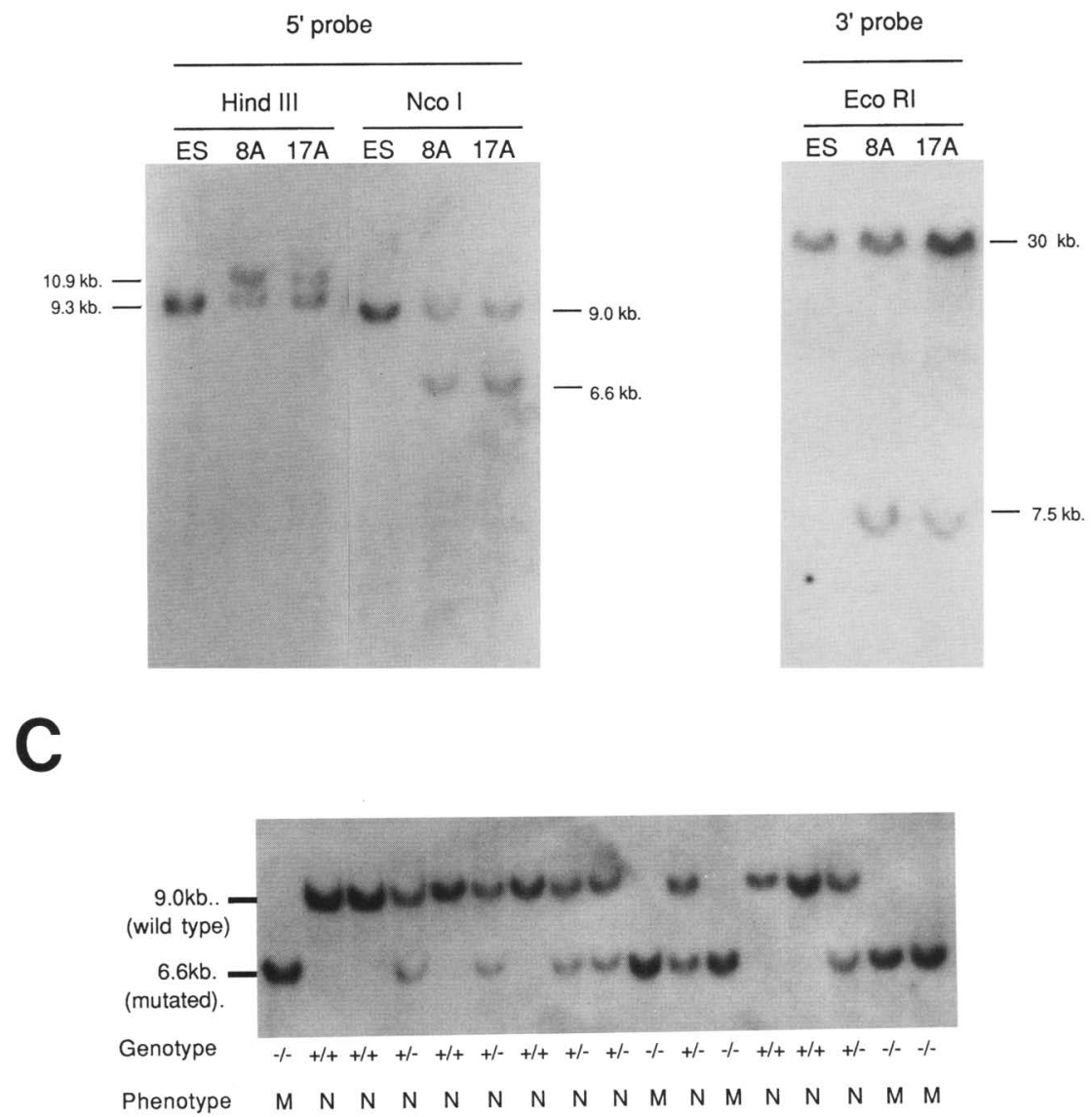

the Wnt-3a targeting strategy. The PGKneobpA gene (Soriano et al. 1991) was inserted into a SmaI site (amino acid position 106; Roelink and Nusse, 1991) in the third exon of Wnt-3a and the selection cassette flanked by 0.8 $\mathrm{kb}$ of $5^{\prime}$ - and $4.7 \mathrm{~kb}$ of $3^{\prime}$-genomic homology. Thus, a successful gene replacement at the Wnt-3a locus should result in truncation of the normal Wnt-3a open reading frame, producing a small protein product approximately one-third of the normal size. As all similarly truncated alleles of Wnt-1 (McMahon and Moon 1989) and the
Drosophila counterpart wingless (A. Martinez-Arias, pers. comm.) are invariably inactive, we expect that successful targeting will generate a null allele of Wnt-3a.

The targeting construct was transfected into the J7 ES cell line (P. Swiatek, F. Franco del Amo, and T. Gridley, in prep.|, and homologous recombinants were detected by PCR (data not shown). Of 192 G418- and FIAU-resistant clones, 2 gave the predicted PCR amplification product. These clones, $8 \mathrm{~A}$ and $17 \mathrm{~A}$, were analyzed by Southern analysis using $5^{\prime}$ - and $3^{\prime}$-specific probes, which flank 
the area of homology in the targeting vector (Fig. 3A). HindIII and NcoI digests of genomic DNA give predicted $10.9-\mathrm{kb}$ and $6.6-\mathrm{kb}$ hybridizing bands, respectively, with the $5^{\prime}$-flanking probe (Fig. 3B), indicative of correct Wnt$3 a$ targeting. Similarly, an expected $7.5-\mathrm{kb} E c o$ RI fragment was detected in both targeted ES cell lines using the $3^{\prime}$ probe (Fig. 3B). Thus, both clones exhibited the expected gene replacement at the Wnt-3a locus. Hybridization with a neo probe failed to detect any additional sites of integration (data not shown).

Targeted ES cells were used to generate chimeras, several of which transmitted the mutated alleles through the germ line. Adult mice heterozygous for targeted alleles were intercrossed to generate homozygous offspring, and litters were genotyped between 1 and 3 weeks after birth by Southern blot analysis. No homozygous offspring were recovered (Table 1), and no significant early postnatal lethality was observed. Thus, loss of Wnt-3a function results in embryonic lethality.

To determine when embryonic lethality occurred and to examine Wnt-3a homozygous mutant embryos, litters were taken at 9.5 to $12.5 \mathrm{dpc}$. Yolk sac DNA from embryos was examined by Southern blot analysis for wildtype or targeted alleles (Fig. 3C). Approximately $25 \%$ of the embryos recovered at 9.5 and $10.5 \mathrm{dpc}$ were homozygous for the targeted alleles, and $85 \%$ of these were viable (Table 1). However, only $17 \%$ of the homozygous mutant embryos were recovered alive at $12.5 \mathrm{dpc}$ (Table 1). Thus, loss of Wnt-3a function leads to embryonic lethality between 10.5 and $12.5 \mathrm{dpc}$.

\section{Axial truncation in Wnt-3a mutants}

Wnt-3a homozygous mutant embryos from both the 8A and $17 \mathrm{~A}$ lines gave identical phenotypes that were readily apparent at $9.5 \mathrm{dpc}$. Anterior development appeared normal; however, caudal to the forelimbs, the

Table 1. Embryonic and postnatal survival of progeny from Wnt-3a-1+ heterozygous intercrosses

\begin{tabular}{|c|c|c|c|c|}
\hline Stage $^{a}$ & & $+1+$ & Wnt $-3 a^{-1+}$ & $\begin{array}{l}\text { Wnt-3a-/ } \\
\text { Wnt-3a-b }(\%)\end{array}$ \\
\hline \multirow[t]{2}{*}{9.5} & A & 9 & 17 & $11(85)$ \\
\hline & $\mathrm{D}$ & 0 & 0 & 2 \\
\hline \multirow[t]{2}{*}{10.5} & A & 9 & 9 & $11(100)$ \\
\hline & $\mathrm{D}$ & 0 & 0 & 0 \\
\hline \multirow[t]{2}{*}{11.5} & A & 4 & 8 & $2(28)$ \\
\hline & $\mathrm{D}$ & 0 & 0 & 5 \\
\hline \multirow[t]{2}{*}{12.5} & A & 10 & 13 & $1(17)$ \\
\hline & $\mathrm{D}$ & 0 & 0 & 5 \\
\hline Postpartum & A & 39 & 77 & $0(0)$ \\
\hline
\end{tabular}

${ }^{a}$ Embryos were genotyped at 9.5-12.5 dpc and neonates at 1-3 weeks after birth. Results are pooled from lines derived from $8 \mathrm{~A}$ or 17A ES cell chimeras. No differences in survival or phenotype were observed between these two lines. Embryos were scored as alive $(A)$ or dead $(D)$ at the time of collection.

${ }^{b}$ Figures in parentheses represent the percentage of Wnt-3aWnt $-3 a^{-}$embryos that were alive at each collection stage. trunk was shortened, the somites were disrupted or missing, and the neural tube was highly kinked (Fig. 4B). All homozygous mutant embryos displayed this phenotype. Thus, the observed axial truncation is completely penetrant. By $12.5 \mathrm{dpc}$, homozygous mutant embryos, which have little or no caudal development posterior to the forelimb, show massive shortening of the axis relative to wild-type or heterozygous embryos (Fig. 4F). Interestingly, two mutant embryos had a single midline hindlimb at the caudal extremity of the truncated axis (data not shown). This suggests that in at least some embryos the hindlimb fields are formed but presumably fuse at the center of the truncated axis to give a single limb in the normal position of the tail. Despite the severe axial truncation, mutant embryos do establish a chorioallantoic placenta with a good embryonic circulation at $9.5 \mathrm{dpc}$. Thus, formation of the yolk sac mesoderm and allantois does not appear to require Wnt-3a. However, it is quite likely that axial truncation leads to circulatory complications, and this factor probably leads to embryonic death at later stages.

\section{Dorsal mesoderm development is defective in Wnt-3a mutants}

The axial truncations observed in Wnt-3a homozygous mutants suggest that gastrulation is severely disrupted. To examine the phenotype in more detail we performed histological analysis at $9.5 \mathrm{dpc}$. Rostral to the forelimbs, Wnt-3a mutant embryos show a normal organization of mesodermal derivatives. The notochord is present at the midline (data not shown), and the first seven to nine somites appear to be developing normally generating dermatome, myotome, and sclerotome derivatives (Fig. $5 \mathrm{~A}, \mathrm{~B})$. In contrast, at the level of the forelimb, somites appear to be entirely absent (Fig. 5C,D). The neural tube is folded and kinked leading to multiple cross-sections through the spinal cord at this axial level (Fig. 5C,D). Notochord is present at the level of the forelimbs (Fig. $5 \mathrm{C}, \mathrm{D} \mid$ but is absent in more posterior regions just caudal to the forelimb buds (data not shown). Finally, in the caudal-most region of the mutant axis there is extensive cell death, which is largely restricted to the dorsal-most mesodermal cells, and no visible tailbud formation (data not shown). These results suggest that absence of Wnt$3 a$ primarily affects development of the somites but has additional consequences for notochord and tailbud formation.

To determine exactly which cell types are present in mutant embryos and how these are organized along the body axis, we performed whole-mount in situ hybridization with a number of probes to identify specific mesodermal populations. At $9.5 \mathrm{dpc}$, expression of the homeo box-containing Mox-1 gene is restricted to presomitic mesoderm and developing somites (Candia et al. 1992). In Wnt-3a mutants, no Mox-1 expression is seen caudal to somites 7-9 (Fig. 6A,B), even when embryos were completely cleared in benzyl alcohol/benzyl benzoate (Davis et al. 1991; data not shown). Thus, Wnt-3a is not required for development of somites up to the level of 


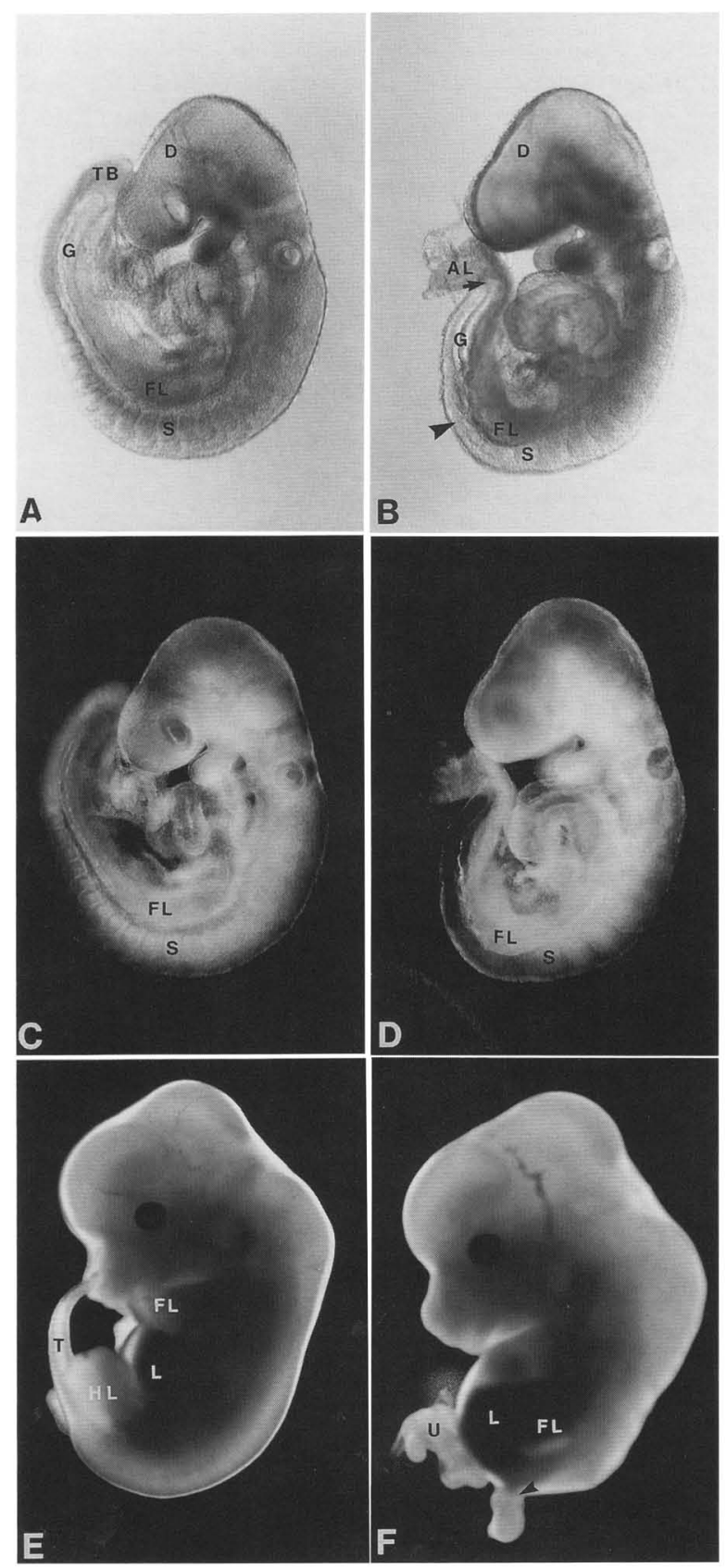

Figure 4. Phenotype of $W n t-3 a^{-} / W n t-3 a^{-}$embryos at 9.5 and $12.5 \mathrm{dpc}$. $(A-D)$ 9.5-dpc embryos; $(A, B)$ bright-field and $(C, D)$ dark-field views. $(E, F)$ Dark-field view of 12.5-dpc embryos. At $9.5 \mathrm{dpc}$, formation of the first seven to nine somites (S) up to the level of the forelimb bud (FL) is normal; however, no somites are visible from the forelimbs caudal (arrowhead). In wild-type and heterozygous embryos, the tailbud (TB) is forming at this stage. No tailbud is visible in the homozygous mutant embryo (arrow), and the axis in truncated. At $12.5 \mathrm{dpc}(\mathrm{F}\rangle$, caudal development has ceased at the level of the umbilicus (U) just anterior to where the hindlimbs (HL) normally form. Wild-type embryos show extensive tail ( $\mathrm{T}$ ) development, whereas mutant embryos occasionally have a small degenerate structure (arrowhead) just caudal to the forelimbs. Diencephalic (D) development appears normal in homozygous mutant embryos; $(\mathrm{AL})$ allantois; $(\mathrm{G})$ gut; (L) liver. the forelimb bud but is required for development of more posterior somites. In contrast to the dorsally located somites, ventral (lateral) mesoderm expressing the Wnt-2 gene, which extends from the heart to the allantois (McMahon and McMahon 1989; Fig. 6C), is present in Wnt-3a mutant embryos (Fig. 6D). Thus, Wnt-3a is apparently not required at similar axial levels for generation of more ventral mesodermal cell types.

To address notochord and tailbud development in Wnt-3a homozygous mutants, expression of the Brachyury and Wnt-5a genes was examined. Brachyury expression, which is indistinguishable in embryos that are wild-type or heterozygous for the targeted Wnt-3a allele, is localized to the notochord along much of the body axis (Fig. 6E). In contrast, in Wnt-3a homozygous mutants, notochord expression is disrupted caudal to the forelimb buds (Fig. 6F). Although a clear notochord is not seen in the posterior region of Wnt-3a mutants, scattered Brachyury-expressing cells are visible, usually in two streams on either side of the midline, suggesting that notochordal cells are formed but not organized into a midline structure (Fig. 6F). In addition, we obtained no evidence for tailbud formation by examining Brachyury (Fig. 6F), Wnt-5a (Fig. 6G,H), or Wnt-3a (data not shown) expression. Taken together, our results suggest that Wnt $-3 a$ is initially required at late egg cylinder stages for somite development, but by late primitive streak/tailbud stages, formation of all mesodermal precursors is dependent, directly or indirectly, on Wnt-3a signaling. The resulting cessation of gastrulation results in truncation of the axis.

\section{Disruption of CNS morphogenesis in Wnt-3a mutants}

From early somite stages, Wnt-3a is expressed in the developing CNS. Expression is initiated in the diencephalon and spinal cord (McMahon et al. 1992; Parr et al. 1993). By 9.5-9.75 dpc, Wnt-3a-expressing cells extend along the dorsal midline of the neural tube from the telencephalon to the base of the developing spinal cord. (Fig. 2; Parr et al. 1993). Moreover, expression extends ventrally in the diencephalon in a localized domain that may correspond to a diencephalic segment (Fig. 2; Parr et al. 1993). Thus, Wnt-3a signaling is implicated in regulating both dorsoventral patterning and forebrain segmentation in the mammalian CNS. To determine whether either of these processes is affected by the loss of Wnt-3a, we examined CNS development in Wnt-3a mutants.

The neural tube anterior to the forelimbs was morphologically and histologically indistinguishable among homozygous, heterozygous, and wild-type embryos (Figs. 4 and 5). Moreover, examination of Wnt-3a expression at $9.75 \mathrm{dpc}$ failed to detect any differences in the normal anterior domain of Wnt-3a expression in the CNS (Fig. 7A,B). However, from the forelimbs caudal, CNS morphogenesis was highly abnormal. The spinal cord was kinked, and dorsal fusion of the neural tube was frequently absent. The phenotype is readily apparent in transverse sections at the level of the forelimbs, where 


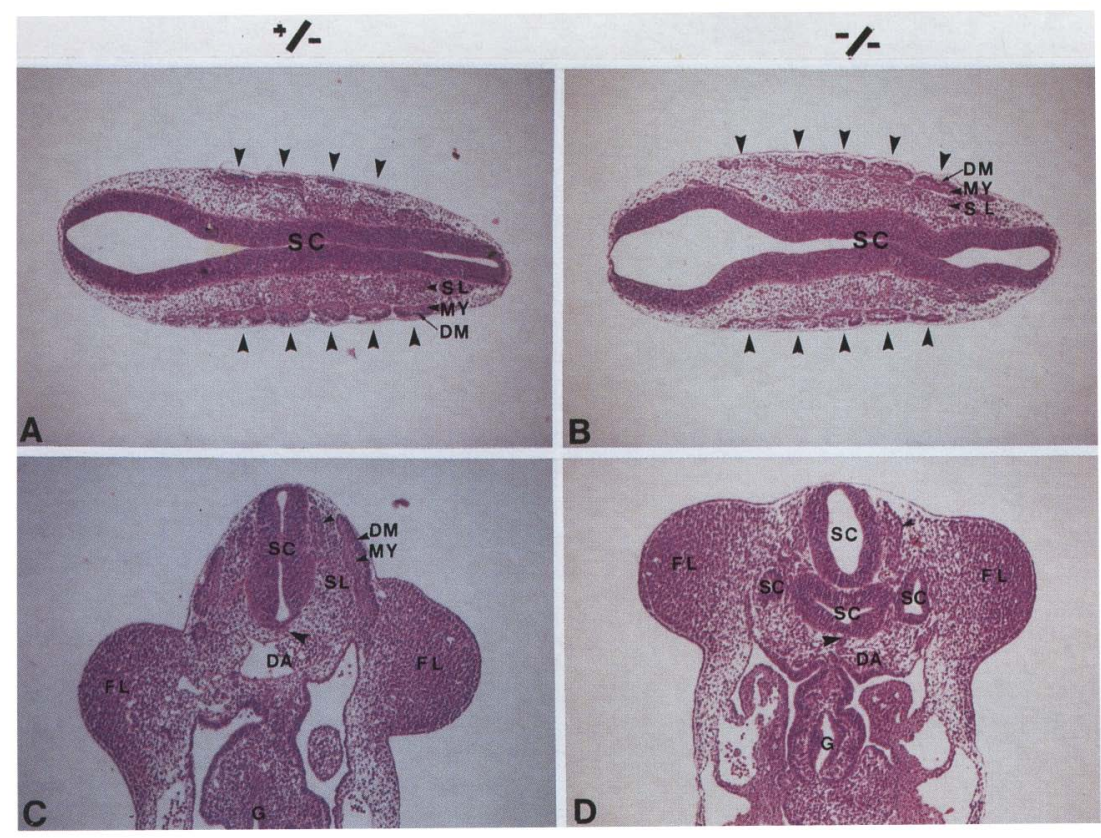

Figure 5. Histological sections through 9.5-dpc embryos heterozygous and homozygous for a targeted Wnt-3a allele. $(A, B)$ In horizontal sections anterior to the forelimb, spinal cord $(\mathrm{SC})$ and somite (arrowhead) development appears normal. At this axial level somites are differentiating into dermatomal (DM), myotomal (MY), and sclerotomal (SL) derivatives. $\quad(C, D)$ Transverse sections at the level of the forelimb (FL) show an absence of somite development in mutant $(-1-)$ embryos and severe dysmorphology of the spinal cord. The clump of cells adjacent to the upper spinal cord section are probably migrating neural crest cells (small arrowhead). The notochord is present at the forelimb level (large arrowhead). (DA) Dorsal aorta; (G) gut. multiple spinal cord sections can be seen, due in part to kinking and folding of the main neuraxis under more caudal regions but also to the apparent pinching off of small isolated patches of neural tissue (Fig. 5D).

To address dorsoventral patterning, we examined expression of three dorsally restricted genes, Pax -3, Wnt-1, and Wnt-3a. Pax-3 is expressed in approximately the dorsal half of the neural tube from the diencephalon to the tailbud at $9.5 \mathrm{dpc}$, as well as in the somites (Fig. 7C,E). In Wnt-3a-/Wnt-3a- embryos, Pax-3 expression shows a similar dorsal restriction extending to the end of the trunk region (Fig. 7D). However, normal dorsomedial Pax-3 expression is perturbed in the kinked and open neural plate, commencing at the position where somites are first absent (Fig. 7D,F). Moreover, in regions where the notochord is severely disrupted or missing, Pax-3 expression extends ventrally (Fig. 7D,F).

Wnt-1, which is normally expressed in a similar if not identical domain to Wnt-3a along much of the dorsal CNS, with the exception of the telencephalon and metencephalon (Fig. 7G), is also correctly expressed at the dorsal aspects forelimb level of the neural tube in Wnt$3 a$ mutant embryos, up to the forelimb level. Like Pax-3, Wnt-1 expression extends in the open neural plate to the caudal limit of the embryo and then projects rostrally as the neural tube turns through $180^{\circ}$ at the end of the truncated axis (Fig. 7H). Patches of separated neuroepithelium continue to express Wnt-1. Similar results were obtained examining Wnt-3a expression in Wnt-3a mutant embryos (data not shown).

Wnt-1 expression was examined more closely in serial

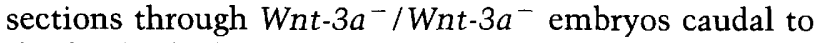
the forelimbs (Fig. 8). Initially, three sites of Wnt-1 expression are seen: two dorsal areas corresponding to the open neural plate and one site corresponding to the dorsal region of a more rostral area of the CNS that has folded under the open neural plate in the caudal part of the mutant embryo. Interestingly, in progressively more caudal sections through this embryo, a fourth site of Wnt-1 expression appears $180^{\circ}$ opposite the existing site in the underfolded spinal cord (Fig. 8B-D). Ectopic expression of Wnt-1 correlates with the position of the neural tube in relation to the surface ectoderm. When separated from the ectoderm by mesenchymal cells, no Wnt-1 expression is observed (Fig. 8A). However, as the underlying neuroepithelium approaches (Fig. $8 \mathrm{~B}, \mathrm{C}$ ) and eventually abuts the surface ectoderm (Fig. 8D), ectopic activation of Wnt-1 expression is observed.

\section{Discussion}

Our studies demonstrate that 3 of the 12 Wnt family members examined are expressed in the primitive streak and tailbud of the mouse embryo. Wnt-5a and Wnt-5b are expressed from the earliest stages of primitive streak formation, whereas broad Wnt-3a expression is not detected until the primitive streak is fully extended along the proximodistal axis of the egg cylinder $(7.5 \mathrm{dpc})$. As well as temporal differences in the expression of these family members, there are clear differences in the location of Wnt transcripts in epiblast and mesodermal cells within the primitive streak and tailbud. Thus, at egg cylinder stages, Wnt-5a and Wnt-5b expression is predominant in the most posterior region of the primitive streak; Wnt-5b is located medially in epiblast and mesoderm, and Wnt-5a is medial-laterally located in mesoderm. In contrast, Wnt-3a expression extends in medial epiblast and mesoderm along the entire length of the 


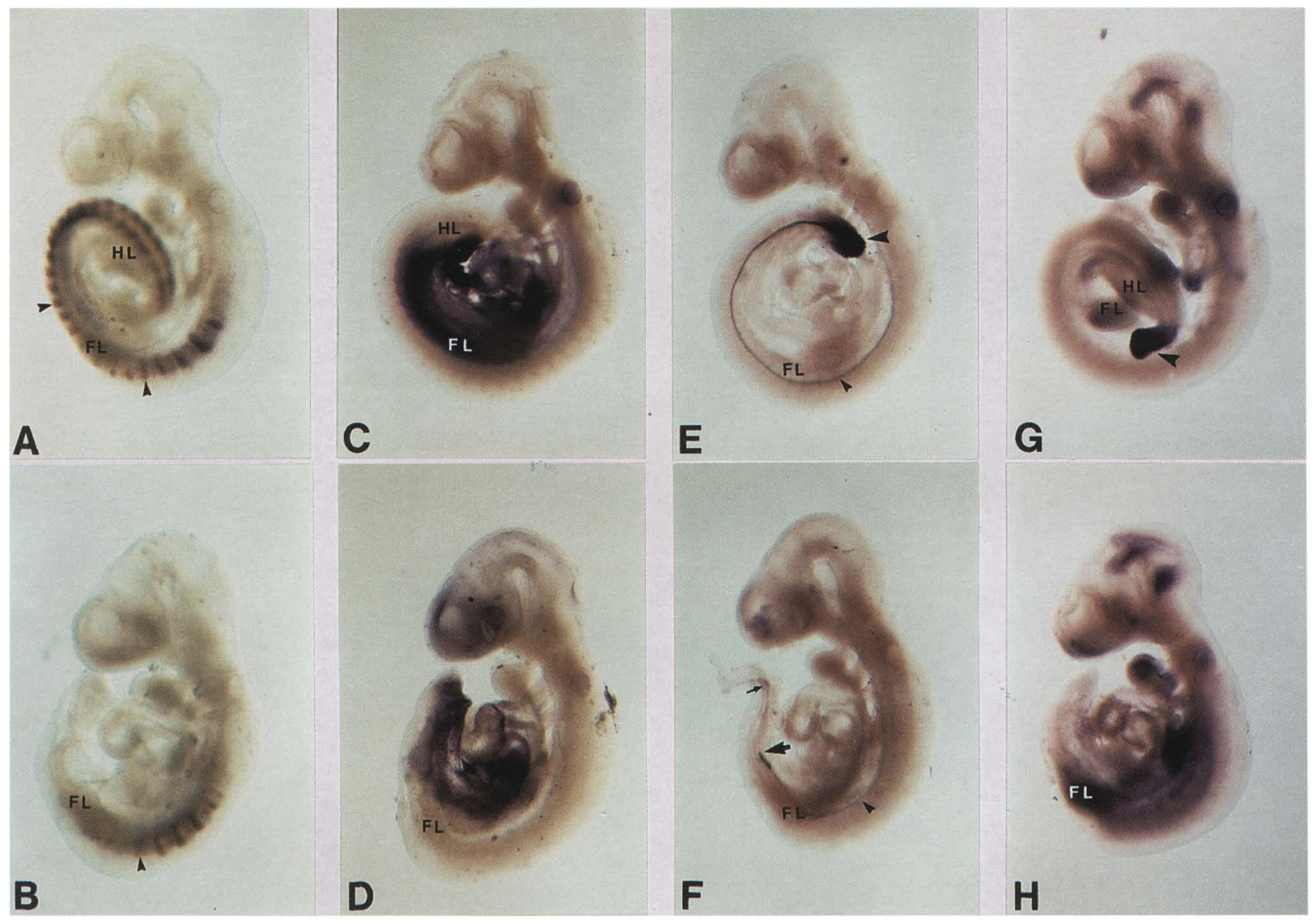

Figure 6. Whole-mount in situ hybridization of mesodermal markers to Wnt-3a homozygous mutant embryos at $9.5 \mathrm{dpc} .(A, C, E, G)$ $+/+$ or $W n t-3 a^{-} /+$embryos (identical results were obtained with wild-type or heterozygous embryos); $(B, D, F, H) W n t-3 a^{-} / W_{n t}-3 a^{-}$ embryos. $(A, B)$ Mox-1 expression in somitic mesoderm. Hybridization is seen to all somites in $+/+$ or $W n t-3 a^{-} /+$embryos $($arrowheads), whereas Wnt-3a-/Wnt-3a- embryos only show hybridization to somites rostral to the forelimb (FL). (C,D) Wnt-2 expression in ventral mesoderm. Expression is normal, in $W n t-3 a^{-} / W n t-3 a^{-}$embryos, extending to the caudal limits of the truncated axis. $(E, F)$ Brachyury expression in tailbud (large arrowhead) and notochord (small arrowhead). Normal notochord morphology terminates caudal to the forelimbs in Wnt-3a-/Wnt-3a- embryos (large arrow). However, a few Brachyury-expressing cells are visible in two discontinuous streams on either side of the mutant embryo (small arrow in $F) .(G, H)$ Wnt-5a expression in the tailbud is entirely absent in Wnt $-3 a^{-} /$Wnt $-3 a^{-}$embryos (large arrowhead). In contrast, Wnt-5a is expressed normally in the CNS, branchial arches, and limbs. (HL) Hindlimb.

primitive streak. In the late primitive streak and tailbud, Wnt- $3 a$ and Wnt-5b expression becomes localized to the caudal-most region of the tail, whereas Wnt-5a expression extends rostrally, occupying a broad region at the posterior end of the embryo. Assuming that Wnt transcripts are translated at these stages and give rise to biologically active peptides, these results suggest that there may be several diverse aspects to Wnt signaling in the regulation of mammalian gastrulation.

\section{Wnt expression domains and mesodermal fate}

A clear picture of the normal fate of epiblast cells in distinct regions of the primitive streak of the mouse em- bryo at different stages has come from a variety of different approaches, including single-cell labeling (Lawson et al. 1991; Lawson and Pedersen 1992), orthotopic grafting (Beddington 1981, 1982, 1983; Tam and Beddington 1987, 1992; Tam 1989), and culture of embryonic fragments (Snow, 1981). These studies have established that although cell types may not be irrevocably committed to specific cell fates in different regions at the streak epiblast (Beddington 1981, 1982, 1983) there is a predictable regional establishment of specific cell populations within the gastrulating embryo.

A fate map for the 7.5-dpc late-streak mouse embryo (R. Beddington, pers. comm.) is illustrated in Figure 9 relative to Wnt gene expression at the same stage. The most posterior region of the primitive streak gives rise to predominantly extraembryonic mesoderm, which lines 

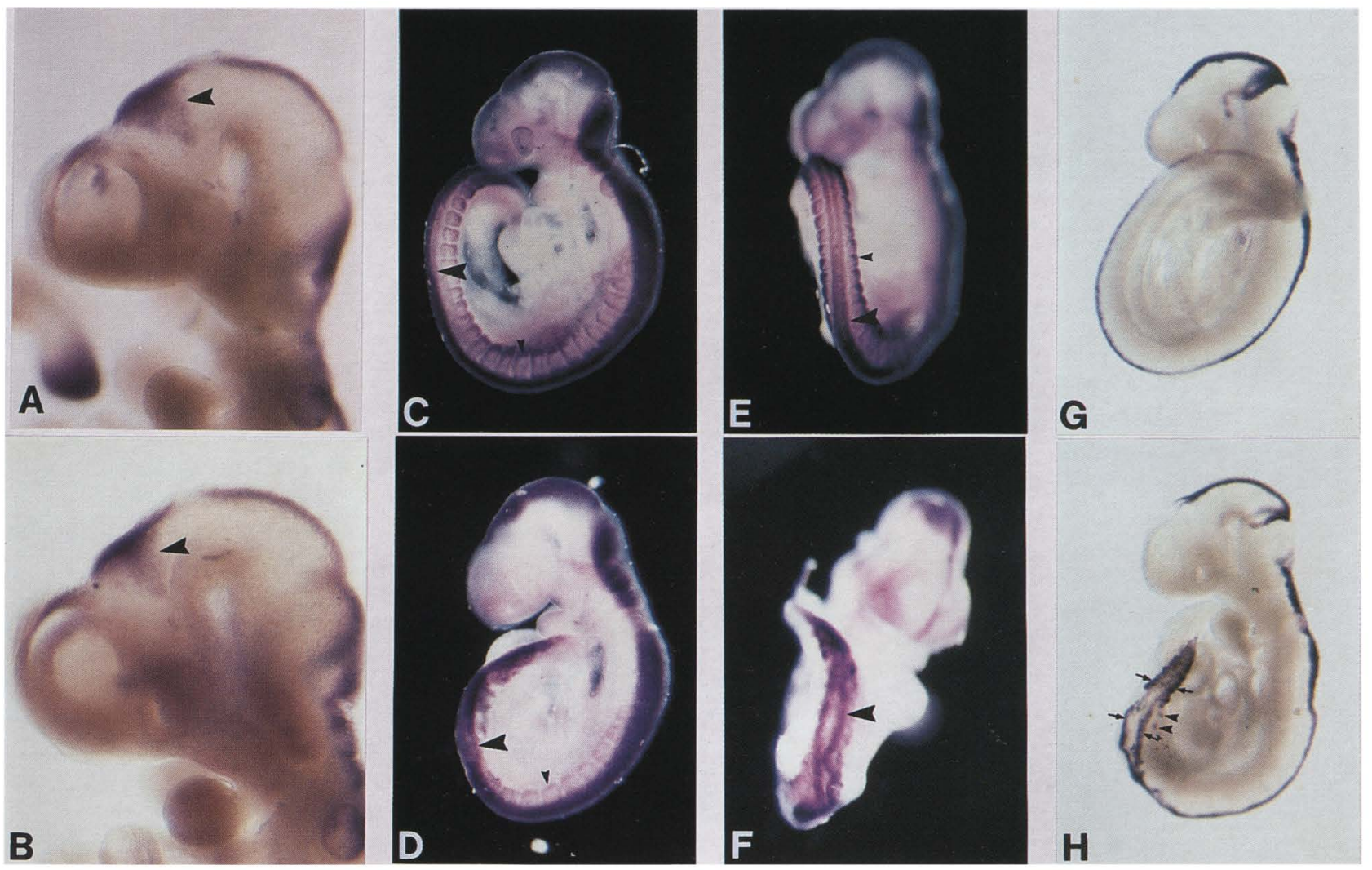

Figure 7. Whole-mount in situ hybridization of CNS markers to Wnt-3a homozygous mutant embryos at $9.5 \mathrm{dpc} .(A, C, E, G)+/+$ or Wnt-3a- $/+$ embryos; $(B, D, F, H)$ Wnt-3a- $/ W n t-3 a^{-}$embryos. $(A, B)$ Expression of Wnt-3a is unaltered in the diencephalon of Wnt$3 a^{-} /$Wnt $-3 a^{-}$embryos (arrowhead); $(C, D)$ sagittal $;(E, F)$ dorsal views of $P a x-3$ expression in the somites (small arrowhead) and dorsal spinal cord (large arrowhead). Pax-3 expression shows normal dorsally restricted expression in the dorsal half of the CNS in Wnt$3 a^{-} / W n t-3 a^{-}$embryos except in the most caudal region where notochord development is disrupted. $(G, H)$ Wnt-1 expression at the dorsal midline of the midbrain, hindbrain, and spinal cord is normal up to the level of the forelimb but becomes split laterally (small

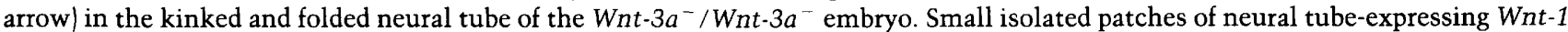
can also be seen (small arrowhead).

the yolk sac and gives rise to embryonic blood cells. In contrast, the mid- and anterior streaks, at late egg cylinder stages, form exclusively embryonic mesoderm. The mid-streak gives rise to the ventral (lateral) mesoderm that lines body cavities and generates mesodermal derivatives such as the kidney, whereas the anterior streak forms the paraxial somitic mesoderm. The definitive endoderm and dorsal midline of the notochord and head process are formed at the most extreme anterior end of the streak from the node region.

Expression of Wnt genes in distinct regions of the primitive streak correlates with regional diversity in the formation of mesodermal subtypes in the mouse embryo, suggesting that Wnt genes may regulate these processes. Expression of Wnt-5a and Wnt-5b, at egg cylinder stages largely overlaps the region that gives rise to extraembryonic mesoderm In contrast, Wnt-3a expression extends into the region that generates embryonic mesoderm. As there is some overlap in the expression domains, there is no simple association of Wnt gene expression with extraembryonic and embryonic cell fates.
Thus, it is possible that some cells expressing $W n t-3 a$, or within the Wnt-3a-expressing region, may give rise to extraembryonic mesoderm. Similarly, some Wnt-5a/ Wnt $-5 b$-expressing cells may generate lateral mesoderm. However, it is clear that the majority of cells expressing Wnt $-5 a / W n t-5 b$ and Wnt-3a at egg cylinder stages do have distinct fates in the conceptus.

At present, relatively little is known concerning the biological properties of Wnt family members; however, the few studies indicate that Wnt-5a and presumably Wnt $-5 b$, to which it shares much higher sequence conservation ( $87 \%$ amino acid identity) than to other $W n t$ members (average $50 \%$ amino acid identity), are functionally distinct from Wnt-3a. For example, Wnt-3a, like Wnt-1, will transform C57MG mammary epithelial cells, whereas Wnt-5a and Wnt-5b are inactive or only weakly active (G. Wong, B. Gavin, and A. McMahon, in prep.). Moreover, ectopic expression in Xenopus embryos of Wnt-3a, but not Wnt-5a, results in axial duplication (Moon et al. 1993; Wolda et al. 1993). Thus, it is tempting to suggest that Wnt-5a/Wnt-5b and Wnt-3a signaling 


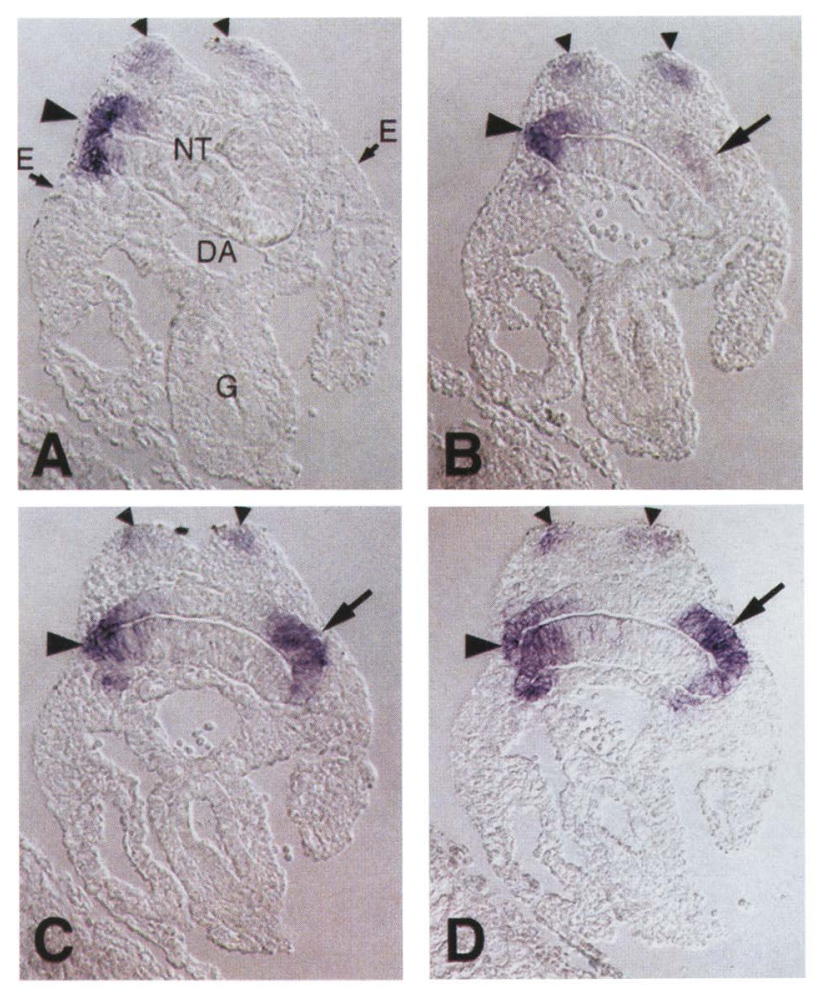

Figure 8. Wnt-1 expression in transverse sections through the

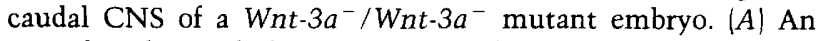
open dorsal neural plate is visible in this and all other sections and, as expected, expresses Wnt-1 at the unfused dorsal aspects (small arrowhead). A more rostral region of closed neural tube (NT) has folded under the open neural plate and expresses Wnt-1 (large arrowhead) where contact is made with the surface ectoderm (E). No expression is seen elsewhere in the closed neural tube. $(B-D)$ More caudal sections through the same embryo. As the neural tube moves toward $(B, C)$ and eventually abuts $(D)$ the surface ectoderm, a new site of Wnt-1 expression occurs $180^{\circ}$ from the preexisting site of Wnt-1 expression (large arrowhead). Expression is weak where the neural tube approaches the surface ectoderm $(B)$ but becomes strong when contact with the surface ectoderm is established (D). (DA) Dorsal aorta; $(\mathrm{G})$ gut.

during early gastrulation may be necessary for the generation of specific mesodermal subtypes. Interestingly, Wnt $-5 a$ and $W n t-5 b$ are all strongly expressed in the late streak and tailbud stage embryo. At this stage there is no new contribution of streak or tailbud precursors to extraembryonic mesoderm (Tam and Beddington 1987). Thus, Wnt-5a and Wnt-5b may have different roles during early and late phases of gastrulation.

\section{Regulation of embryonic mesoderm by Wnt-3a}

Whereas the role of Wnt-5a and Wnt-5b remains a matter for speculation, Wnt-3a is clearly essential for embryonic, but not extraembryonic, mesoderm formation. A detailed analysis of mesodermal cell types in Wnt-3a mutants at $9.5 \mathrm{dpc}$ suggests that the earliest defect occurs in the loss of somites at, and caudal to, the level of the forelimb. Although the notochord is disrupted in more posterior regions of the embryo, notochord development at the forelimb level is normal. A subset of ventral mesoderm that expresses Wnt-2 is largely unaffected but terminates prematurely as a result of the axial truncation that results from the loss of Wnt-3a expression. These results suggest a number of possible functions for Wnt-3a signaling during mouse gastrulation.

Wnt-3a expression extends, at late egg cylinder stages, into anterior primitive streak cells fated to give rise to the somites (Fig. 9). These appear to be the predominant cell types expressing Wnt-3a alone. Thus, Wnt-3a may be required to specify somitic cell fate. If this is the case, then the most anterior seven to nine somites that form normally are specified by a Wnt-3a independent pathway. Wnt-3a is not expressed at high levels until $7.5 \mathrm{dpc}$; thus, somites 1-7 may be specified prior to the activation of Wnt-3a. There is some support for this idea from orthotopic grafting of labeled epiblast from the anterior streak at $7.5 \mathrm{dpc}$ (Tam and Beddington 1987). Grafted cells only give rise to presomitic mesoderm after culture to the somite stage six, suggesting that these labeled cells will give rise to somites caudal to the sixth somite. However, epiblast labeling by injection of wheat germ agglutinin into the amniotic cavity at similar stages suggests that labeled epiblast cells can contribute to somites rostral to somite 6 (Tam and Beddington 1987). Additional grafting studies suggest that these cells may be derived from more posterior-lateral regions adjacent to the primitive streak (Tam 1989). The different outcomes of these approaches presumably reflect technical differences in the experiments. Thus, at present it remains unclear whether somites that are independent of Wnt-3a form prior to Wnt-3a expression. Interestingly, Brachyury mutants that encode a defective $T$ gene product first show notochordal defects at a similar axial level to Wnt-3a mutants (Beddington et al. 1992) even though the $T$ gene is activated at the start of gastrulation. Thus, there may be some common aspect to the developmental program governing formation of different mesodermal cell types that is initiated later in gastrulation.

From $7.5 \mathrm{dpc}$ to $7.75 \mathrm{dpc}$, Wnt-3a expression moves anterior in the primitive streak to terminate just posterior to the node, the region that gives rise to the notochord (Fig. 9; Tam and Beddington 1987; Lawson et al. 1991). Thus, Wnt-3a, which encodes a secreted protein (L. Burrus and A. McMahon, in prep.), may directly regulate the development of notochord precursors in the node, after initial notochord formation has commenced. Interestingly, Wnt-3a has recently been shown to have dorsalizing properties when ectopically expressed in $\mathrm{Xe}$ nopus embryos (Wolda et al. 1993) consistent with Wnt$3 a$ normally regulating notochord development. In Wnt$3 a^{-} /$Wnt $-3 a^{-}$embryos notochord morphogenesis is disrupted. However, notochord cells are not entirely absent but are present in low numbers and fail to form a midline notochord, caudal to the forelimbs. Thus, there does not appear to be an absolute requirement for Wnt-3a activity to generate notochordal precursors at an axial level where somites are entirely absent.

In addition to the somitic and notochordal disruptions, 


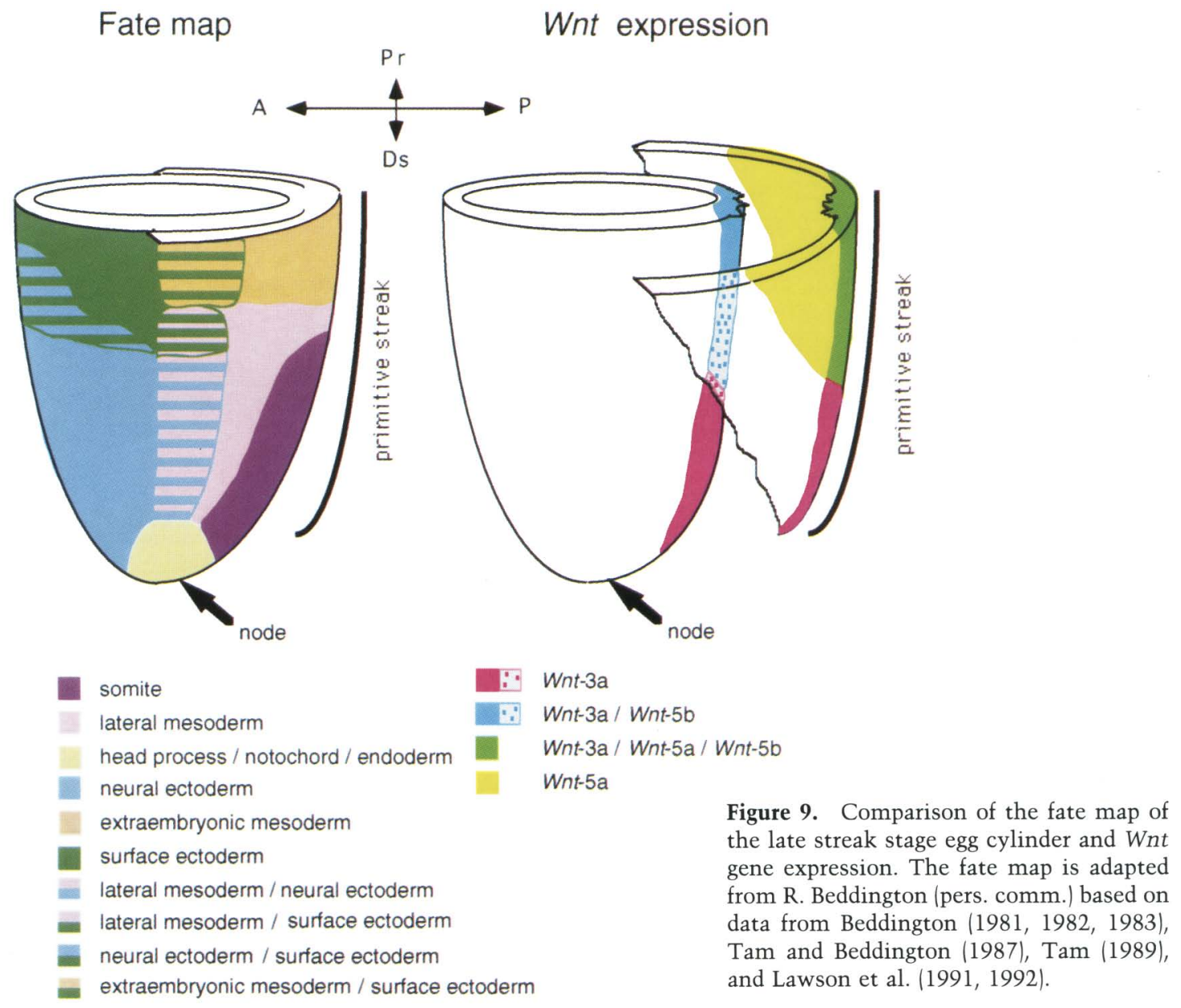

no tailbud is formed in Wnt-3a homozygous mutant embryos. The tailbud is established from cells deriving from the mid-streak region (Snow 1981), a population of cells localized midway along the proximodistal axis of Wnt-3a expression at $7.5 \mathrm{dpc}$. Thus, Wnt $-3 a$ may play an additional role in establishing the mesodermal precursors that become localized to the tailbud. Loss of this cell population may then lead to axial truncation, a result consistent with physical extirpation of the tailbud region in the mouse embryo (Smith 1964).

Wnt-3a may function in the assignment of several embryonic mesodermal cell fates as discussed above. Alternatively, a similar phenotype may result if Wnt-3a is required for normal mitogenic activity within the embryonic mesodermal precursors of the primitive streak and early tailbud. Cessation of cell proliferation would be expected to lead to mesodermal and axial truncation after all mesodermal precursors have differentiated. The observed rostral-caudal loss of somites, then notochord, and the apparently normal development of at least some ventral mesodermal cell types would suggest that distinct regions of the embryonic mesoderm "run out" of precursor cells before others. To distinguish between these various hypotheses will require further work. Moreover, it is clear that there are a large number of other peptide signaling molecules and their receptors that are expressed in the gastrulating mouse embryo, including members of the FGF, TGF- $\beta$, and platelet-derived growth factor families (for review, see Faust and Magnuson 1993). Two of these have been shown to regulate mesoderm formation. Nodal mutants, which lack a member of the TGF- $\beta$ superfamily (Zhou et al. 1993), show little evidence of mesoderm formation (Conlon et al. 1991; Iannaccone et al. 1992). In contrast, mutants in the FGF-3 gene are adult viable, with disruption of only the caudal-most mesodermal derivatives in the tail (Mansour et al. 1993), despite the fact that FGF-3 is expressed from $6.5 \mathrm{dpc}$ in the primitive streak (Wilkinson et. al. 1988). Thus, regulation of mesoderm formation is likely to be complex, requiring the combinatorial action of multiple factors operating at different developmental stages. However, our studies establish a central role for the Wnt-3a gene in regulation of embryonic mesoderm formation and suggest that Wnt-5a and Wnt-5b may 
have distinct nonoverlapping functions during gastrulation.

\section{Wnt-3a and neural development}

At $9.5 \mathrm{dpc}$, Wnt $-3 a$ is expressed along much of the dorsal midline of the CNS and in a triangular "compartment" in the diencephalon. Thus, Wnt-3a is implicated in diencephalic segmentation (Figdor and Stern 1993) as well as the establishment of dorsoventral polarity in the CNS (Parr et al. 1993). At and caudal to the forelimb, the neural tube is abnormally kinked and folded in Wnt-3a-/ Wnt $-3 a^{-}$embryos. Dysmorphology of the spinal cord occurs precisely at the axial level where the somites are absent and not in more rostral areas where Wnt-3a is also expressed. Thus, the somites may be required to physically constrain, or to regulate cell growth, in the neural tube. Interestingly, in Brachyury mutants, where somite formation is disrupted, neural tube folding and kinking are also observed. It appears that the neural tube continues to expand in Wnt-3a mutants. In the absence of an elongating trunk this may also lead to the observed folding and compression of the caudal CNS. Thus, it is likely that the CNS dysmorphology occurs secondarily to the loss of neighboring somites and truncation of the axis.

We have addressed the issue of dorsal patterning within the Wnt-3a-deficient neural tube by examining the expression of three dorsal markers, Wnt-1, Wnt-3a, and Pax-3. All are expressed normally up to the point at which CNS morphology is perturbed, suggesting that Wnt-3a is not required, at least to the forelimb level, for CNS patterning. Severe disruption in CNS patterning is observed in more caudal regions, although this is most likely a secondary consequence of disruption of neural tube morphogenesis and loss of the underlying notochord.

In caudal regions, failure of the neural tube to close leads to two dorsolateral domains, instead of a single dorsal midline domain, of Wnt-1 and Pax-3 expression. Loss of the notochord results in dorsal Pax-3 expression moving ventrally as reported for notochordal removals in the early chick embryo (Goulding et al. 1993). The most interesting aspect of the pattern alteration is that of ectopic Wnt-1 expression in the neural tube. Loss of flanking somites and compression of the neural tube allow new points of contact to be made between the neural tube and surface ectoderm, which lead to ectopic activation of Wnt-1. This result suggests that dorsal patterning in the CNS may be initiated by ecotodermally derived signals. As high-level expression of Wnt-1 occurs where close apposition is seen between the CNS and surface ectoderm, these signals may act quite locally, in an analogous fashion to those of the notochord, which induce the ventral floor plate (Jessel and Melton 1992).

In summary, the CNS phenotypes are best explained as secondary consequences of the loss of mesodermal derivatives rather than the loss of dorsal Wnt-3a expression in the CNS. Wnt-3a and Wnt-1 colocalize in much of the dorsal CNS, and we have suggested that they may have a redundant function (McMahon et al. 1992). As the hindbrain and spinal cord up to the forelimbs are normal, in both Wnt-1 and Wnt-3a mutants, analysis of compound mutant embryos may be required to reveal additional roles for a combined Wnt-1/Wnt-3a signaling pathway in this area of the dorsal CNS.

\section{Materials and methods}

Wnt-3a targeting

Genomic phage $\lambda$ clones encompassing the Wnt-3a locus were isolated by screening a BALB/c genomic library with a Wnt-3a cDNA probe (Roelink and Nusse 1991). A plasmid, p3A39SH, was generated that contained a $5.8-\mathrm{kb}$ SphI-HindIII Wnt-3a genomic fragment, including exon 3 together with $0.8 \mathrm{~kb}$ of $5^{\prime}$ and $4.7 \mathrm{~kb}$ of $3^{\prime}$-flanking sequence. A blunt-ended 1.6-kb HindIII-XhoI fragment containing the phosphoglycerate kinase-1 (PGK-1) promoter, neomycin phosphotransferase gene, and bovine growth hormone polyadenylation sequences (PGKneobpA; Soriano et al. 1991) was ligated into a unique SmaI site in exon 3 of p3A39SH in the opposite transcriptional orientation to the Wnt-3a gene. The insert was then excised by SalI-HindIII digestion and ligated into XhoI-HindIII-digested pMClTK (Mansour et al. 1988) to generate the final targeting construct pWnt3 aneoTK. This vector was linearized at a unique ClaI site in the plasmid polylinker at the $5^{\prime}$ end of the Wnt-3a sequence before electroporation.

Subconfluent ES cells from the fibroblast feeder layer-dependent 77 cell line (P. Swiatek, F. Franco del Amo, and T. Gridley, in prep.) were resuspended at a cell density of $1.2 \times 10^{7}$ cells $/ \mathrm{ml}$ in PBS with $25 \mu \mathrm{g} / \mathrm{ml}$ of linearized pWnt-3aneoTK. Electroporation culture and selection (G418 and FIAU) were as described previously (McMahon and Bradley 1990).

G418- and FIAU-resistant colonies were picked into feeder layer (primary embryo fibroblast) containing 48-well plates 6-8 days after electroporation. After 3-4 days of additional culture, one-third of the trypsinized cells from six individual wells were pooled, centrifuged, resuspended in $20 \mu \mathrm{l}$ of PCR-DNA extraction buffer $(16.6 \mathrm{mM}$ ammonium sulfate, $67 \mathrm{mM}$ Tris- $\mathrm{HCl}$ at $\mathrm{pH}$ 8.8, $6.7 \mathrm{mM} \mathrm{MgCl}_{2}, 5 \mathrm{mM} \beta$-mercaptoethanol, $6.7 \mu \mathrm{M}$ EDTA, 1.7 $\mu \mathrm{M}$ SDS, $50 \mu \mathrm{g} / \mathrm{ml}$ of proteinase $\mathrm{K})$, and incubated at $37^{\circ} \mathrm{C}$ overnight. Proteinase $\mathrm{K}$ was inactivated at $85^{\circ} \mathrm{C}$ for $10 \mathrm{~min}$. The remaining two-thirds of the cell pellet was resuspended in DMEM containing $10 \%$ DMSO and $15 \%$ fetal bovine serum and stored at $-75^{\circ} \mathrm{C}$.

PCR was carried out using $5 \mathrm{ml}$ of each lysate in $1 \times$ PCR buffer (no SDS or proteinase $\mathrm{K}$ ), 10\% DMSO, $1 \mathrm{~mm}$ each $\mathrm{dNTP}$, and $1 \mu \mathrm{M}$ each primer (Soriano et al. 1991). The following primers were used to detect a $1.6-\mathrm{kb}$ band indicative of homologous recombination at the Wnt-3a locus: a second intron primer lying just upstream of the SphI site at the 5' end of the targeting vector (TTCTTTTGTAGTGTAGCCTTGGCTG) and a sense strand oligonucleotide from the 3 ' end of the neomycin phosphotransferase gene (TGGCTACCCGTGATATTGCT). Samples were amplified for 40 cycles $193^{\circ} \mathrm{C}$ for $30 \mathrm{sec} ; 55^{\circ} \mathrm{C}$ for 30 sec; $65^{\circ} \mathrm{C}$ for $3 \mathrm{~min}$ ), and $\mathrm{PCR}$ products were then resolved by electrophoresis through a $1.5 \%$ agarose gel. Amplified bands were visualized by ethidium bromide staining. To confirm that the observed PCR products did correspond to the expected region, DNA was transferred to nylon membrane and hybridized with an internal oligonucleotide probe. This procedure was repeated for DNA samples prepared from individual clones from positive pools to identify specific targeted colonies. 
Final confirmation of Wnt-3a targeting and germ-line transmission was obtained by Southern blot analysis of ES cell clones and offspring from chimeric and $F_{1}$ crosses using the diagnostic probes and digests indicated in Fig. 3A. Genotyping of newborn mice and embryos was performed by Southern analysis with DNA samples prepared from tail and yolk sac biopsies, respectively. Hybridization was carried out in $50 \%$ formamide, $6 \times$ SSC, $0.1 \%$ SDS, $1 \times$ Denhardt's solution, $20 \mathrm{~mm}$ phosphate buffer ( $\mathrm{pH} 7.3$ ), $200 \mu \mathrm{g} / \mathrm{ml}$ of yeast tRNA, and $10 \%$ dextran sulfate at $42^{\circ} \mathrm{C}$ for $16 \mathrm{hr}$. Final washes were performed in $0.1 \times$ SSC at $60^{\circ} \mathrm{C}$.

\section{Generation of ES cell chimeras}

ES cells from the two correctly targeted lines, 8A and 17A, were injected into C57BL/6J (Jackson Laboratories) or MF1 (Harland Sprague-Dawley/ recipient blastocysts to generate chimeras as described (Bradley 1987). Chimeric males were intercrossed to C57BL/6J females, and agouti offspring were genotyped for transmission of the mutated Wnt-3a alleles. Intercrosses were then set up between heterozygous $F_{1}$ offspring to generate homozygous Wnt-3a-/Wnt-3a- progeny.

\section{Histology and in situ hybridization}

To obtain sections through normal or Wnt-3a mutant embryos, embryos or decidua were dissected into PBS, fixed in either $4 \%$ paraformaldehyde (in situ and general histological analysis) or Bouin's fixative (general histological analysis), and processed for wax embedding (Kaufman 1992). Sections for general histological analysis were dewaxed in xylene, rehydrated through an ethanol series into PBS, and stained with hematoxylin and eosin. In situ hybridization to tissue sections was performed as described (Wilkinson et al. 1987b). Whole-mount in situ hybridization was performed essentially as described by Wilkinson (1992). After in situ hybridization, embryos were fixed in $4 \%$ paraformaldehyde, $0.1 \%$ glutaraldehyde, prior to wax embedding and sectioning. This step is essential in preserving the chromogenic precipitate through xylene and ethanol, step 5. Whole-mount embryos and sections through whole-mount embryos were mounted in $80 \%$ glycerol in PBS.

Sections were photographed using bright-field, Nomarski, or dark-field optics using a Leitz Orthoplan II compound microscope on Fuji Velvia 64 ASA or Fujichrome 64T color slide film. Double exposures were generated as described by McMahon et al. (1992). Embryo whole mounts were photographed in $80 \%$ glycerol using an Olympus SZH stereophotomicroscope on Fujichrome 64T slide film.

The following probes were used in the in situ expression studies: Brachyury (Herrmann 1991); Wnt-1 (Fung et al. 1985); Wnt-2 (McMahon and McMahon 1989); Wnt-3a (Roelink and Nusse 1991); Wnt-5a (Gavin et al. 1990); Wnt-5b (Gavin et al. 1990); Pax-3 (Goulding et al. 1991); and Mox-1 (Candia et al. 1992).

\section{Acknowledgments}

We are grateful to Drs. Roel Nusse, Bernhard Herrmann, Peter GrCss, and Chris Wright for gifts of Wnt-3a, Brachury, Pax-3, and Mox-1 cDNA probes, respectively. We also thank Dr. Ross Kinloch for the mouse genomic library and Dr. Tom Gridley for the ES cell line. We are particularly indebted to Dr. Rosa Beddington for permission to adapt her diagram of cell fate in the late streak epiblast and for many useful discussions. S.T. was supported by a postdoctoral fellowshp from the Human Frontiers Science Program.
The publication costs of this article were defrayed in part by payment of page charges. This article must therefore be hereby marked "advertisement" in accordance with 18 USC section 1734 solely to indicate this fact.

\section{References}

Amaya, E., T.J. Musci, and M.W. Kirschner. 1991. Expression of a dominant negative mutant of the FGF receptor disrupts mesoderm formation in Xenopus embryos. Cell 66: 257-270.

Beddington, R.S.P. 1981. An autoradiographic analysis of the potency of embryonic ectoderm in the 8th day postimplantation mouse embryo. J. Embryol. Exp. Morphol. 64: 87-104. - 1982. An autoradiographic analysis of tissue potency in different regions of the embryonic ectoderm during gastrulation in the mouse. J. Embryol. Exp. Morphol. 69: 265-285.

- 1983. The origin of the foetal tissues during gastrulation in the rodent. Development in mammals (ed. M.H. Johnson), pp. 1-27. Elsevier Science Publishers B.V.

Beddington, R.S.P., A.W. Püschel, and P. Rashbass. 1992. Use of chimeras to study gene function in mesodermal tissues during gastrulation and early organogenesis. CIBA Found. Symp. 165: 61-77.

Bradley, A. 1987. Production and analysis of chimaeric mice. In Teratocarcinomas and embryonic stem cells: A practical approach (ed. E.J. Robertson), pp. 113-151. IRL Press, Oxford, UK.

Candia, A.F., J. Hu, P.A. Crosby, D. Lalley, D. Noden, J.D. Nadeau, and C.V.E. Wright. 1992. Mox-1 and Mox-2 define a novel homeobox gene subfamily and are differentially expressed during early mesodermal patterning in mouse embryos. Development 116: 1123-1136.

Christian, J.L. and R.T. Moon. 1993. Interactions between $X w n t-8$ and Spemann organizer signaling pathways generate dorsoventral pattern in the embryonic mesoderm of Xenopus. Genes \& Dev. 7: 13-28.

Christian, J.L., J.A. McMahon, A. McMahon, and R.T. Moon. 1991. Xwnt-8, a Xenopus wnt-1/int-1-related gene responsive to mesoderm-inducing growth factors, may play a role in ventral mesodermal patterning during embryogenesis. Development 111: 1045-1055.

Christian, J.L., D.J. Olson, and R.T. Moon. 1992. Xwnt-8 modifies the character of mesoderm induced by bFGF in isolated Xenopus ectoderm. EMBO I. 11: 33-41.

Conlon, F.L., K.S. Barth, and E.J. Robertson. 1991. A novel retrovirally induced embryonic lethal mutation in the mouse: Assessment of the developmental fate of embryonic stem cells homozygous for the 413.d proviral integration. Development 111: 969-981.

Cunliffe, V. and J.C. Smith. 1992. Ectopic mesoderm formation in Xenopus embryos caused by widespread expression of Brachyury homologue. Nature 358: 427-430.

Davis, C.A., D.P. Holmyard, K.J. Millen, and A.L. Joyner. 1991. Examining pattern formation in mouse, chicken, and frog embryos with an En-specific antiserum. Development 111: 287-298.

Faust, C. and T. Magnuson. 1993. Genetic control of gastrulation in the mouse. Curr. Opin. Genet. Dev. 3: 491-498.

Figdorf, M.C. and C.D. Stern. 1993. Segmental organization of embryonic diencephalon. Nature 363: 630-634.

Fung, Y.-K.T., G.M. Shackleford, A.M.C. Brown, G.S. Sanders, and H.E. Varmus. 1985. Nucleotide sequence and expression in vitro of cDNA derived from mRNA of int-1, a provirally activated mouse mammary oncogene. Mol. Cell. Biol. 5: 3337-3344. 
Gavin, B., J.A. McMahon, and A.P. McMahon. 1990. Expression of multiple novel Wnt-1/int-1-related genes during fetal and adult mouse development. Genes \& Dev. 4: 2319-2332.

Goulding, M.D., G. Chalepakis, U. Deutsch, J.R. Erselius, and P. Gruss. 1991. Pax-3, a novel murine DNA binding protein expressed during early neurogenesis. $E M B O /$. 10: 1135-1147.

Goulding, M.D., A. Lumsden, and P. Gruss. 1993. Signals from the notochord and floor plate regulate the region-specific expression of two Pax genes in the developing spinal cord. Development 117: 1001-1016.

Hemmati-Brivanlou, A. and D.A. Melton. 1992. A truncated activin receptor inhibits mesoderm induction and formation of axial structures in Xenopus embryos. Nature 359: 609661.

Herrmann, B.G. 1991. Expression pattern of the Brachyury gene in whole-mount $\mathrm{T}^{\mathrm{Wis}} / \mathrm{T}^{\mathrm{Wis}}$ mutant embryos. Development 113: 913-917.

1992. Action of the Brachyury gene in mouse embryogenesis. Postimplantation development in the mouse. CIBA Found. Symp. 165: 78-91.

Iannaccone, P.M., X. Zhou, M. Khokha, D. Boucher, and M.R. Kuehn. 1992. Insertional mutation of a gene involved in growth regulaton of the early mouse embryo. Dev. Dynamics 194: 198-206.

Jessell, T.M. and D.A. Melton. 1992. Diffusible factors in vertebrate embryonic induction. Cell 68: 257-270.

Kaufman, M.H. 1992. The atlas of mouse development. Academic Press, London, UK.

Kimelman, D., J.A. Abraham, T. Haaparanta, T.M. Palisi, and M.W. Kirschner. 1988. The presence of fibroblast growth factor in the frog egg: Its role as a natural mesoderm inducer. Science 242: 1053-1056.

Lawson, K.A., J.J. Meneses, and R.A. Pedersen. 1991. Clonal analysis of epiblast fate during germ layer formation in the mouse embryo. Development 113: 891-911.

Lawson, K.A. and R.A. Pedersen. 1992. Clonal analysis of cell fate during gastrulation and early neurulation in the mouse. Postimplantation development in the mouse. CIBA Found. Symp. 165: 3-26.

Mansour, S.L., K.R. Thomas, and M.R. Capecchi. 1988. Disruption of the proto-oncogene int-2 in mouse embryo-derived stem cells: A general strategy for targeting mutations to nonselectable genes. Nature 336: 348-352.

Mansour, S.L., J.M. Goddard, and M.R. Capecchi. 1993. Mice homozygous for a targeted disruption of the proto-oncogene int-2 have developmental defects in the tail and inner ear. Development 117: 13-28.

McMahon, A.P. 1992. The Wnt-family of developmental regulators. Trends Genet. 8: 236-242.

- 1993. Cell signalling in induction and anterior-posterior patterning of the vertebrate central nervous system. Curr. Opin. Neurobiol. 3: 4-7.

McMahon, A.P. and A. Bradley. 1990. The Wnt-1 (int-1) protooncogene is required for development of a large region of the mouse brain. Cell 62: 1073-1085.

McMahon, A.P. and R.T. Moon. 1989. Ectopic expression of the proto-oncogene int-1 in Xenopus embryos leads to duplication of the embryonic axis. Cell 58: 1075-1084.

McMahon, A.P., A.L. Joyner, A. Bradley, and J.A. McMahon. 1992. The midbrain-hindbrain phenotype of Wnt-1 $1^{-} / W n t-$ $1^{-}$mice results from stepwise deletion of engrailed-expressing cells by 9.5 days post coitum. Cell 69: 581-595.

McMahon, J.A. and A.P. McMahon. 1989. Nucleotide sequence, chromosomal localization and developmental expression of the mouse int-1-related gene. Development 107: 643-651.

Moon, R.T. 1993. In pursuit of the functions of the Wnt family of developmental regulators: Insights from Xenopus laevis. BioEssaays 15: 91-97.

Nusse, R. and H.E. Varmus. 1992. Wnt-genes. Cell 69: 10731087.

Parr, B., M. Shea, G. Vassileva, and A. McMahon. 1993. Mouse Wnt-genes exhibit discrete domains of expression in the early embryonic CNS and limb buds. Development (in press).

Roelink, H. and R. Nusse. 1991. Expression of two members of the Wnt family during mouse development-restricted temporal and spatial patterns in the developing neural tube. Genes \& Dev. 5: 381-388.

Schoenwolf, G.C. 1977. Tail (end) bud contributions to the posterior region of the chick embryo. J. Exp. Zool. 201: 227-246.

Sive, H.L. 1993. The frog prince-ss: A molecular formula for dorsoventral patterning in Xenopus. Genes \& Dev. 7: 1-12.

Slack, J.M.W. and D. Tannahill. 1992. Mechanisms of anteriorposterior axis specification in vertebrates. Development 114: 285-302.

Slack, J.M.W., B.G. Darlington, J.K. Heath, and S.F. Godsave. 1987. Mesoderm induction in early Xenopus embryos by heparin-binding growth factors. Nature 326: 197-200.

Smith, J.C. 1987. A mesoderm inducing factor is produced by a Xenopus cell line. Development 99: 3-14.

Smith, I.C., B.M.J. Price, K. Vannimmen, and D. Huylebroeck. 1990. Identification of a potent Xenopus mesoderm-inducing factor as a homologue of activin-A. Nature 345: 729-731.

Smith, L.J. 1964. The effects of transection and extirpation on axis formation and elongation in the young mouse embryo. J. Embryol. Exp. Morphol. 12: 787-803.

Smith, W.C. and R.M. Harland. 1991. Injected Xwnt-8 RNA acts early in Xenopus embryos to promote formation of a vegetal dorsalizing center. Cell 67: 753-766.

Snow, M.H.L. 1981. Autonomous development of parts isolated from primitive-streak-stage mouse embryos. Is development clonal? J. Embryol. Exp. Morphol. 65: 269-287.

Sokol, S., G.G. Wong, and D.A. Melton. 1990. A mouse macrophage factor induces head structures and organizes a body axis in Xenopus. Science 249: 561-564.

Sokol, S., J.L. Christian, R.T. Moon, and D.A. Melton. 1991 Injected Wnt-RNA induces a complete body axis in Xenopus embryos. Cell 67: 741-752.

Soriano, P., C. Montgomery, R. Geske, and A. Bradley. 1991 Targeted disruption of the $c$-src proto-oncogene leads to osteoporosis in mice. Cell 64: 693-702.

Tam, P.P.L. 1989. Regionalisation of the mouse embryonic ectoderm: Allocation of prospective ectodermal tissues during gastrulation. Development 107: 55-67.

Tam, P.P.L. and R.S.P. Beddington. 1987. The formation of mesodermal tissues in the mouse embryo during gastrulation and early organogenesis, Development 99: 109-126.

1992. Establishment and organization of germ layers in the gastrulating mouse embryo. Postimplantation in the mouse. CIBA Found. Symp. 165: 27-49.

Thomas, K.R. and M.R. Capecchi. 1990. Targeted disruption of the murine int-l proto-oncogene resulting in severe abnormalities in midbrain and cerebellar development. Nature 346: $847-850$.

Thomas, K.R., T.S. Musci, P.E. Neumann, and M.R. Capecchi. 1991. Swaying is a mutant allele of the proto-oncogene Wnt1. Cell 67: 969-976.

Thomsen, G.H. and D.A. Melton. 1993. Processed Vgl protein is an axial mesoderm inducer in Xenopus. Cell 74: 433-441.

Wilkinson, D.G. 1992. In situ hybridization: A practical approach. Oxford University Press.

Wilkinson, D.G., J.A. Bailes, and A.P. McMahon. 1987a. Expres- 
sion of the proto-oncogene int-1 is restricted to specific neural cells in the developing mouse embryo. Cell 50: 79-88.

Wilkinson, D.G., J.A. Bailes, J.E. Champion, and A.P. McMahon. 1987b. A molecular analysis of mouse development from 8 to 10 days post coitum detects changes only in embryonic globin expression. Development 99: 493-500.

Wilkinson, D.G., G. Peters, C. Dickson, and A.P. McMahon. 1988. Expression of the FGF-related proto-oncogene int-2 during gastrulation and neurulation in the mouse. EMBO $J$. 7: 691-695.

Wilkinson, D.G., S. Bhatt, and B.G. Herrmann. 1990. Expression pattern of the mouse $\mathrm{T}$ gene and its role in mesoderm formation. Nature 343: 657-659.

Wolda, S.L., C.J. Moody, and R.T. Moon. 1993. Overlapping expression of Xwnt-3A and Xwnt-1 in neural tissue of Xenopus laevis embryos. Dev. Biol. 155: 46-57.

Zhou, X., H. Sasaki, L. Lowe, B.L.M. Hogan, and M.R. Kuehn. 1993. Nodal is a novel TGF-El-like gene expressed in the mouse node during gastrulation. Nature 361: 543-546. 


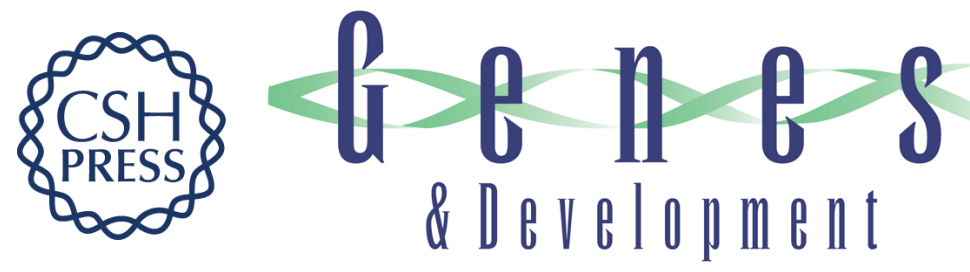

\section{Wnt-3a regulates somite and tailbud formation in the mouse embryo.}

S Takada, K L Stark, M J Shea, et al.

Genes Dev. 1994, 8:

Access the most recent version at doi:10.1101/gad.8.2.174

References This article cites 60 articles, 19 of which can be accessed free at: http://genesdev.cshlp.org/content/8/2/174.full.html\#ref-list-1

License

Email Alerting

Receive free email alerts when new articles cite this article - sign up in the box at the top Service right corner of the article or click here.

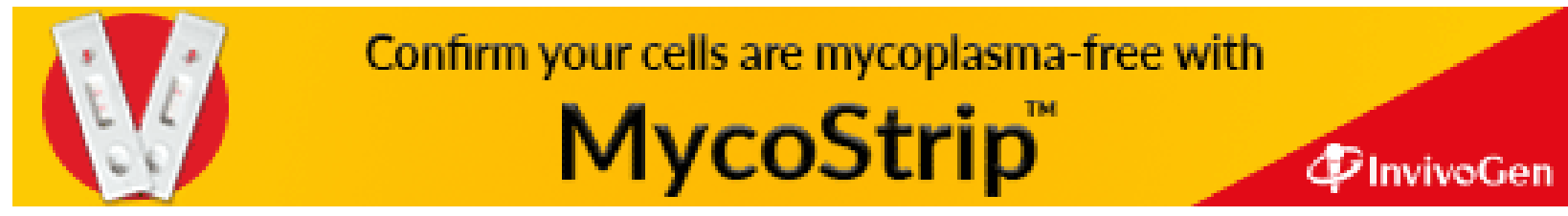

